\title{
THE INFLUENCE OF OIL PRICE ON RENEWABLE ENERGY STOCK PRICES: AN ANALYSIS FOR ENTREPRENEURS
}

\section{Georgiana Vrînceanu*}

Bucharest University of Economic Studies, Romania

E-mail: vrinceanugeorgianal6@stud.ase.ro

\section{Alexandra Horobet}

The Bucharest University of Economic Studies, Romania

E-mail: alexandra.horobet@rei.ase.ro

\section{Consuela Popescu}

The Bucharest University of Economic Studies, Romania

E-mail : consuela.popescu@rei.ase.ro

\section{Lucian Belașcu}

"Lucian Blaga" University of Sibiu, Romania

E-mail: lucian.belascu@ulbsibiu.ro

(Received: March 2020; Accepted: April 2020; Published: June 2020)

\begin{abstract}
This study investigates the relationship between oil price fluctuations and renewable energy stock returns using daily data on Brent crude oil prices and global renewable energy stock market indices between 29 November 2010 and 18 February 2020. The investigation is based on the existing evidence on positive correlations between stock prices and oil prices, but it also considers the shift from non-renewable to renewable sources of energy. A two-stage $\operatorname{GARCH}(1,1)$ model and a Granger causality test were applied. Our results show that volatility clustering is present in the renewable energy companies' stock prices, but, oil price volatility does not seem to induce any significant effects on returns' volatility. This might suggest that oil markets and renewable energy markets are rather disconnected, which means that the development of renewable energy businesses is less affected by potential shocks in the oil prices and markets. As a result, the exposure of companies and entrepreneurs in the renewable sector to an important source of macroeconomic volatility is reduced.
\end{abstract}

Keywords: oil price; global renewable energy indices; GARCH; Granger Causality

*Corresponding author: Georgiana Vrînceanu. E-mail: vrinceanugeorgianal6@stud.ase.ro

Copyright $(\mathrm{C} 2020$ The Author(s). Published by VGWU Press

This is an Open Access article distributed under the terms of the Creative Commons BY 4.0 license (Creative Commons - Attribution 4.0 International - CC BY 4.0) which permits unrestricted use, distribution, and reproduction in any medium, provided the original author and source are credited. 
JEL Codes: F23, G15, Q42

\section{Introduction}

Nowadays, the global economy is considerably dependent on fossil fuels, such as crude oil and an international concern is that crude oil prices and stock prices seem to be positively correlated. The positive correlation between stock prices and crude oil prices might be explained by the fact that both are responding to some underlying shifts in global demand. In other words, a possible explanation for this positive correlation might be the tendency of stock prices and crude oil prices to react in the same way to common factors, such as changes in aggregate demand or in overall uncertainty and risk aversion.

Renewable energy sources represent extremely important contributors to the energy supply portfolio for the reason that they take part in the global energy supply security, help decrease dependency on fossil fuel resources and also, offer greenhouse gases mitigation opportunities.

This research hypothesis is based on the economy-wide impact and influence of Brent crude oil price movements. Therefore, our main goal consists in analyzing the exposure to oil price fluctuations of a set of eight global renewable energy companies' indices. We believe that this approach is more consistent in proving information on the link between oil prices and stock price, as these indices are, essentially, portfolios of companies that operate in the field of renewable energy. Consequently, our approach is, on one hand, closer to the perspective of institutional investors (that hold portfolios of assets and less individual stocks), and, on the other hand, better equipped to understand the link between oil and nonrenewable energy markets because it mitigates the impact of specific factors on stock prices and returns.

The paper is structured as follows. Section 2 discusses the empirical literature on the relationship between oil price and clean energy stock prices. Section 3 describes the research methodology and the data used for this research. Our findings and results are presented and then discussed in Section 4. Finally, the last section concludes.

\section{Literature review}

In the last years, the study of the relationship between oil price and stock prices, mainly with reference to the impact that oil price volatility has on stock prices of companies active in different sectors of the economy has seen high impetus. Although few studies have observed how fluctuations in oil price affect the return of renewable energy companies' equity prices, there is no clear consensus on the nature of the relationship between these two variables. 
Vrînceanu, G., Horobet, A., Popescu, C., Belașcu, L., (2020)

The influence of oil price on renewable energy stock prices: an analysis for entrepreneurs

The importance of the channels by which oil price dynamics affects the performance of renewable energy companies is acknowledged by investors whenever faced with the decision to invest in renewable energy stocks or not. At the same time, taking into account that public spending is aimed at reducing the dependence on finite resources, it is crucial to understand the impact that movements in oil price might have on the supply of oil. Also, a rise in the oil price might lead to the substitution of alternative energy resources by conventional energy resources.

There have been several articles dealing with the effect of oil prices on renewable energy companies' performance. Sadorsky (2012), Managi et al. (2013), Broadstock et al. (2012) show positive relationships, while Reboredo (2017) renders mixed results. Thus, Sadorsky (2012) used a variable beta model and reported that an increase in oil prices has a positive impact on renewable energy stocks for the period 2002-2007. Furthermore, Managi et al. (2013) analyze the relationship between oil prices, clean energy stock prices and technology stock prices applying Markov-switching vector autoregressive models that endogenously controls for structural changes in the market. Similar to Sadorsky, a positive relationship was found between oil prices and clean energy stock prices only after the structural break of 2007 (the Global financial crisis) in which there was a huge increase in oil price, thus suggesting at the same time a movement from conventional energy to clean energy. Broadstock et al. (2012) also look at the period after the global financial crisis and they find that Chinese investors are more sensitive to shocks in international crude oil prices and that there is a positive correlation between the oil price and energy related stock returns. Moreover, because of financial turmoil, oil markets become more volatile which leads to higher stock returns.

Later on, Bondia et al. (2016) find that technology stock prices, oil prices and interest rates affect alternative energy companies' stock prices in the short-run, but no impact is experienced in the long-run. Similarly, Kumar et al. (2012) demonstrate that clean energy stock prices are affected by oil prices, interest rates and technology stock prices by using a VAR (i.e. Vector Autoregressive) model.

Henriques et al. (2008) showed that for a list of major companies listed on US stock exchange there is proof of Granger causality from oil prices to stock prices for renewable energy companies. Furthermore, Reboredo (2015) studied systemic risk and dependence between oil and renewable energy markets using copulas and found that oil price dynamics contributes around $30 \%$ to the downside and upside risk of renewable energy companies. Later on, the same author - Reboredo (2017) examines the co-movement and causality between oil and renewable energy stock prices using continuous and discrete wavelets. In the short-run, they show that the

26 Sciendo Studia Universitatis "Vasile Goldis" Arad. Economics Series Vol 30 Special Issue 2/2020 ISSN: 1584-2339; (online) ISSN: $2285-3065$

Web: publicatii.uvvg.ro/index.php/studiaeconomia. Pages $24-35$ 
Vrînceanu, G., Horobet, A., Popescu, C., Belașcu, L., (2020)

The influence of oil price on renewable energy stock prices: an analysis for entrepreneurs

relationship between oil and renewable energy returns is weak, but is gradually getting stronger in the long-run. The study renders consistent nonlinear causality from renewable energy indices to oil prices and mixed evidence causality from oil prices to renewable energy indices.

Wen et al. (2014) use an asymmetric Baba-Engle-Kraft-Kroner model and find that renewable energy and fossil fuel stocks have significant mean and volatility spillovers between them. Another study by Dutta (2017) assessed whether the variance of alternative energy stock returns can be explained using OVX (a crude oil volatility index). He uses three different range-based random vector estimators to show that clean energy stock market returns are highly correlated with OVX, as a measure of oil price uncertainty. What is more important, the author reveals that the information contained by OVX improves the volatility forecasts for the clean energy equity markets.

To the best of our knowledge, it is the first time when the relationship between oil price fluctuations and energy stock returns is examined using a two stage GARCH $(1,1)$ model.

\section{Methodology and empirical data}

This study proposes an empirical research on the relationship between oil price changes and stock prices volatility for eight global stock market indices: DAXglobal Alternative Energy Index, NASDAQ OMX Clean Energy Focused Europe Index, NASDAQ OMX Clean Energy Focused US Index, NASDAQ OMX Geothermal Index, NASDAQ OMX Renewable Energy Generation Index, NASDAQ OMX Solar Index, S\&P Global Clean Energy Net Total Return Index and World Alternative Energy Total Return Index in USD Market Capitalization Adjusted. We use daily data of these eight global stock market indices between 29 November 2010 and 18 February 2020 and we calculate daily stock returns. Similarly, daily Brent crude oil prices are used. The data was collected from Bloomberg.

DAXglobal Alternative Energy Index includes corporations from the industry of alternative energies worldwide. For this global index, 5 sub-sectors are relevant: Ethanol, Geothermal/Hydro/Batteries, Natural Gas, Solar and Wind. This index provides the performance of the worldwide fifteen biggest corporations in the field of alternative energy (STOXX, 2016).

The NASDAQ OMX Clean Energy Focused Europe Index is created in order to monitor the sectors of the Green Economy. This index includes corporations from Europe from the following sectors: Renewable Energy, Energy Efficiency, Advanced Materials, and Bio/Clean Fuels. On the other hand, The NASDAQ OMX Clean Energy Focused US Index includes corporations domiciled in the United States of America and from the same sectors (NASDAQ, 2020). 
The NASDAQ OMX Geothermal Index represents a sub-sector index of the Green Economy Index and it was developed in order to monitor corporations that produce energy through geothermal power. Another sub-sector index of the Green Economy Index, which has been used for our research, is The NASDAQ OMX Solar Index. This index was created in order to monitor corporations that produce energy through solar power. Moreover, we use also a primary sector index of the Green Economy Index called The NASDAQ OMX Renewable Energy Generation index. This index was developed in order to monitor corporations that produce energy through renewable sources such as solar, wind, geothermal, wave, and fuel cells (NASDAQ, 2020).

Another global stock market index used for our research is the S\&P Global Clean Energy Index which includes 30 corporations from around the world that are implicated in clean energy related businesses. This global index incorporates a varied combination of clean energy production and clean energy equipment and technology corporations (US S\&P Indices, 2020).

The MSCI Global Alternative Energy Index incorporates developed and emerging market large, mid and small cap corporations that acquire 50\% or more of their revenues from products and services in alternative energy (MSCI, 2020).

The logarithmic transformation of the daily stock returns of the studied financial companies was calculated considering Eq. 1:

$$
R_{i, t}=\operatorname{Ln}\left(\frac{P_{i, t}}{P_{i, t-1}}\right)
$$

where: $R_{i, t}$ is the logarithmic return of the financial company's stock price $i$ in period $t, P_{i, t}$ represents the closing price of the financial company's stock price $i$ in period $t$ and $P_{i, t-1}$ represents the closing price of the financial company's stock price $i$ in period $t-1$. The same logarithmic transformation has been applied to oil prices, as well.

ARCH (Autoregressive Conditional Heteroscedasticity) models were compiled by Engle (1982) and were the first models that proposed a conditional variance process with an autoregressive structure and log returns modelled as a white noise multiplied by the volatility. A few years later, Bollerslev (1986) extended these original models in order to allow the variance $\left(\sigma_{t}^{2}\right)$ to have a supplementary autoregressive structure within itself and created the GARCH (Generalized Autoregressive Conditional Heteroskedasticity) model. The GARCH $(1,1)$ model is applied in the academic literature, being used in financial time series modelling and it consists of two main equations, the first one for the mean and the second one for the variance of the time series: 


$$
\begin{gathered}
R_{t}=\theta X^{\prime}+\epsilon_{t} \\
\sigma_{t}^{2}=\omega+\alpha \epsilon_{t-1}^{2}+\beta \sigma_{t-1}^{2}
\end{gathered}
$$

where: the equation for the mean (Eq. 2) includes exogenous variables (X') and an error term $(\epsilon)$, i.i.d. with an expectation of 0 and variance of 1 . The conditional variance $\sigma_{t}^{2}$ specified in Eq. 3 is the one-period ahead forecast variance based on information from the past $\left(\sigma_{t-1}^{2}\right)$, news about the volatility of the previous period - i.e. the one-period lag of the squared residuals in Eq. 2, or the ARCH term - and the constant $\omega$. The $\operatorname{GARCH}(1,1)$ means that a first-order autoregressive GARCH term (the first 1 in parentheses) and a first-order moving average ARCH term (the second 1 in parentheses) are present in the estimation. The coefficients $\alpha$ and $\beta$ represent the model's parameters.

For our purpose, we apply a two-stage $\operatorname{GARCH}(1,1)$ model proposed in a study that belongs to Omran and McKenzie (2010). The main goal of their research is to investigate whether GARCH modelling succeeds in capturing the effects of temporal dependence in trading volume for individual stocks in the UK market. A feasible explanation for the success of GARCH models in modelling stock returns is represented by the information flow hypothesis. If it is pretended that the mixing variable, the number of information arrival forms a serially dependent sequence, then it is probable that GARCH model is capable to capture the temporal dependence in this variable.

In the first stage of this model we estimate a $\operatorname{GARCH}(1,1)$ for each stock in our sample as follows:

$$
\begin{aligned}
& R_{i, t}=a_{i, 0}+b_{1} R_{i, t-1}+\varepsilon_{i, t} \\
& \sigma_{i, t}^{2}=\alpha_{i, 0}+\alpha_{i, 1} \varepsilon_{i, t-1}^{2}+\beta_{i, 1} \sigma_{i, t-1}^{2}
\end{aligned}
$$

where: $R_{i, t}$ is the logarithmic return of stock prices of the studied financial companies and $\varepsilon_{i, t} \sim N\left(0, \sigma_{i, t}^{2}\right)$. We add in Eq. 4 an autoregressive term of order 1 for the purpose of correcting the small but significant first-order autocorrelation in mean returns. Eq. 5 indicates the variance of unexpected stock return as a GARCH $(1,1)$ process where the sum of parameters $\alpha_{i, 1}$ and $\beta_{i, 1}$, which lies between 0 and 1 , measures the volatility persistence in stock returns.

In the second stage of the model we add a term for oil price change in the conditional variance equation: 
Vrînceanu, G., Horobeț, A., Popescu, C., Belașcu, L., (2020)

The influence of oil price on renewable energy stock prices: an analysis for entrepreneurs

$$
\sigma_{i, t}^{2}=\alpha_{i, 0}+\alpha_{i, 1} \varepsilon_{i, t-1}^{2}+\beta_{i, 1} \sigma_{i, t-1}^{2}+\omega_{i, 1} V_{i, t}
$$

Therefore, if the oil price change represents a proxy for new information that arrives in the market, then the coefficient $\omega_{i, 1}$ is higher than zero and the sum of $\alpha_{i, 1}$ and $\beta_{i, 1}$ becomes negligible. A significant $\omega_{i, 1}$ coefficient would indicate that oil price volatility has a say from the perspective of renewable stock prices' volatility.

In both stages of the model, the parameters are estimated jointly using the BerndtHall-Hall-Hausman optimization algorithm in Eviews and the Q-statistic is used in order to test the hypothesis of the lack of GARCH effects in the residuals (Omran and McKenzie, 2010).

The GARCH $(1,1)$ model is complemented by a Granger causality test on the relationship between stock returns' unconditional volatility and oil price changes. The Granger causality tests were developed by Granger (1969) and represents a statistical concept of causality between two variables in time series data based on prediction power; thus, in terms of Granger causality, a variable $X$ causes (more specifically, Granger-causes) another variable $\mathrm{Y}$ if past values of $\mathrm{X}$ help predicting $\mathrm{Y}$ above and beyond the past values of $\mathrm{Y}$ alone.

\section{Empirical results}

The results of the first-stage $\operatorname{GARCH}(1,1)$ model estimations are presented in Table 1. This is the restricted model where $\omega$ was set equal to zero. We remark that the Q-statistics at the lag 10 for the squared returns $\left(Q_{10}^{2} R\right)$ display statistical significance for all indices, except one. This statistical significance demonstrates the existence of GARCH effects in the indices' returns. Also, these findings indicate that the persistence in volatility as measured by the sum of $\alpha_{1}$ and $\beta_{1}$ is very high in almost all situations, higher than 0.9 in the case of seven out of eight indices. Moreover, we notice that the Q-statistics at the lag 10 for the squared standardized residuals $\left(Q_{10}^{2} U\right)$ do not present significant GARCH effects except for only one index, namely NASDAQ OMX Solar Index.

The next step in our analysis involved the estimation of the second-stage GARCH(1,1) model, the unrestricted model. Table 2 displays the results of the second-stage GARCH $(1,1)$ model estimations. We discover that the coefficient of oil price presents statistical significance for five out of eight indices. As well as in the first-stage $\operatorname{GARCH}(1,1)$ model estimations, the persistence in volatility as measured by the sum of $\alpha_{1}$ and $\beta_{1}$ turned out to be very high in almost all situations, more explicitly, it was higher than 0.9 in the case of seven out of eight indices. Additionally, the $Q$-statistic at the lag 10 for the squared standardized residuals do not show significant GARCH effects except for only one index -

30 S sciendo Studia Universitatis "Vasile Goldis" Arad. Economics Series Vol 30 Special Issue 2/2020 ISSN: 1584-2339; (online) ISSN: $2285-3065$

Web: publicatii.uvvg.ro/index.php/studiaeconomia. Pages $24-35$ 
Vrînceanu, G., Horobet, A., Popescu, C., Belașcu, L., (2020)

The influence of oil price on renewable energy stock prices: an analysis for entrepreneurs

NASDAQ OMX Solar Index again. On the other hand, we notice that the values for the coefficient $\omega_{i, 1}$ are not different than zero, which supports the finding that oil price is not an explanatory variable for the conditional volatility of returns of renewable energy stock indices. Thus, these results suggest that when including the oil price in the variance of indices' returns, the persistence in volatility does not modify significantly and GARCH effects are no longer present in the residuals of this model.

Table 1 Results of the first-stage $\operatorname{GARCH}(1,1)$ model estimations

\begin{tabular}{|c|l|c|c|c|}
\hline & \multicolumn{1}{|c|}{ Index } & $\boldsymbol{\alpha}_{1}+\boldsymbol{\beta}_{1}$ & $\boldsymbol{Q}_{10}^{2} \boldsymbol{R}$ & $\boldsymbol{Q}_{10}^{2} \boldsymbol{U}$ \\
\hline 1 & DAXglobal Alternative Energy Index & 0.984 & $26.226^{*}$ & 12.213 \\
\hline 2 & NASDAQ OMX Clean Energy Focused Europe Index & 0.988 & $20.136^{*}$ & 5.479 \\
\hline 3 & NASDAQ OMX Clean Energy Focused US Index & 0.945 & 3.893 & 11.931 \\
\hline 4 & NASDAQ OMX Geothermal Index & 0.603 & $17.159^{* *}$ & 1.202 \\
\hline 5 & NASDAQ OMX Renewable Energy Generation Index & 0.991 & $41.466^{*}$ & 5.270 \\
\hline 6 & NASDAQ OMX Solar Index & 0.983 & $41.746^{*}$ & $17.829^{* *}$ \\
\hline 7 & S\&P Global Clean Energy Net Total Return Index & 0.974 & $42.443^{*}$ & 12.768 \\
\hline 8 & $\begin{array}{l}\text { World Alternative Energy Total Return Index in USD } \\
\text { Market Capitalization Adjusted }\end{array}$ & 0.963 & $16.026^{* *}$ & 10.421 \\
\hline
\end{tabular}

Note: $Q_{10}^{2} R$ denotes $Q$-statistics at the lag 10 for the squared returns and $Q_{10}^{2} U$ denotes Qstatistics at the lag 10 for the squared standardized residuals. Also, * and ** indicates statistical significance at least at $1 \%$ and $5 \%$ level, respectively

Source: authors' own research results

Table 2 Results of the second-stage GARCH(1,1) model estimations

\begin{tabular}{|c|l|c|c|c|}
\hline \multicolumn{1}{|c|}{ Index } & $\boldsymbol{\omega}_{1}$ & $\boldsymbol{\alpha}_{1}+\boldsymbol{\beta}_{1}$ & $\boldsymbol{Q}_{10}^{2}$ \\
\hline 1 & DAXglobal Alternative Energy Index & $0.000^{*}$ & 0.983 & 15.851 \\
\hline 2 & NASDAQ OMX Clean Energy Focused Europe Index & $0.000^{*}$ & 0.985 & 6.586 \\
\hline 3 & NASDAQ OMX Clean Energy Focused US Index & 0.000 & 0.947 & 10.881 \\
\hline 4 & NASDAQ OMX Geothermal Index & 0.000 & 0.597 & 1.169 \\
\hline 5 & NASDAQ OMX Renewable Energy Generation Index & $0.000^{*}$ & 0.988 & 5.591 \\
\hline 6 & NASDAQ OMX Solar Index & 0.000 & 0.983 & $17.352^{* *}$ \\
\hline 7 & S\&P Global Clean Energy Net Total Return Index & $0.000^{*}$ & 0.972 & 13.019 \\
\hline 8 & $\begin{array}{l}\text { World Alternative Energy Total Return Index in USD } \\
\text { Market Capitalization Adjusted }\end{array}$ & $0.000^{*}$ & 0.966 & 11.677 \\
\hline
\end{tabular}

Note: $*$ and $* *$ indicates statistical significance at least at $1 \%$ and $5 \%$ level, respectively

Source: authors' own research results

The causal relationship between stock prices volatility and oil price changes was tested using the F-statistic test, by applying the Granger Causality approach. The results in Table 3 present the Granger causal relationships between stock prices volatility and oil price changes. The first null hypothesis assumes that stock prices volatility does not Granger causes the oil price and the second null hypothesis 
Vrînceanu, G., Horobet, A., Popescu, C., Belașcu, L., (2020)

The influence of oil price on renewable energy stock prices: an analysis for entrepreneurs

supposes that oil price does not Granger causes stock prices volatility. Thus, our findings reveal that there are no significant unilateral and/or bilateral causal relationships between stock prices volatility and oil price changes. We also observe that in the case of only one out of eight indices (NASDAQ OMX Geothermal Index) oil price changes cause stock prices volatility.

Table 3 Causal relationships between stock price changes and oil price changes

\begin{tabular}{|c|l|c|c|}
\hline \multicolumn{1}{|c|}{ Index } & \multicolumn{2}{|c|}{ F-statistic } \\
\cline { 2 - 4 } & \multicolumn{1}{|c|}{$\begin{array}{c}\text { Null hypothesis: } \\
V O L_{t} \square O I L_{t}\end{array}$} & $\begin{array}{c}\text { Null hypothesis: } \\
O I L_{t} \square V O L_{t}\end{array}$ \\
\hline 1 & DAXglobal Alternative Energy Index & 0.627 & 0.485 \\
\hline 2 & $\begin{array}{l}\text { NASDAQ OMX Clean Energy Focused } \\
\text { Europe Index }\end{array}$ & 0.538 & 0.673 \\
\hline 3 & $\begin{array}{l}\text { NASDAQ OMX Clean Energy Focused US } \\
\text { Index }\end{array}$ & 0.927 & 1.845 \\
\hline 4 & NASDAQ OMX Geothermal Index & 0.280 & $2.808^{* *}$ \\
\hline 5 & $\begin{array}{l}\text { NASDAQ OMX Renewable Energy } \\
\text { Generation Index }\end{array}$ & 0.073 & 0.332 \\
\hline 6 & NASDAQ OMX Solar Index & 0.306 & 0.785 \\
\hline 7 & $\begin{array}{l}\text { S\&P Global Clean Energy Net Total Return } \\
\text { Index }\end{array}$ & 0.235 & 0.515 \\
\hline 8 & $\begin{array}{l}\text { World Alternative Energy Total Return } \\
\text { Index in USD Market Capitalization } \\
\text { Adjusted }\end{array}$ & 0.284 & \\
\hline
\end{tabular}

Note: $V O L_{t}$ denotes return volatility, $O I L_{t}$ denotes oil prices changes and $* *$ indicates statistical significance at least at $5 \%$ level

Source: authors' own research results

\section{Conclusions}

Our study proposes an empirical research regarding the relationship between oil price changes and stock prices volatility for eight global stock market indices: DAXglobal Alternative Energy Index, NASDAQ OMX Clean Energy Focused Europe Index, NASDAQ OMX Clean Energy Focused US Index, NASDAQ OMX Geothermal Index, NASDAQ OMX Renewable Energy Generation Index, NASDAQ OMX Solar Index, S\&P Global Clean Energy Net Total Return Index and World Alternative Energy Total Return Index in USD Market Capitalization Adjusted. Using daily Brent crude oil prices and daily data of these eight global stock market indices between 29 November 2010 and 18 February 2020, we employ a two-stage GARCH $(1,1)$ model and a Granger causality test.

Our results show that GARCH effects are present in the renewable energy companies' stock returns, which is a sign of volatility clustering. This is an 
Vrînceanu, G., Horobeț, A., Popescu, C., Belașcu, L., (2020)

The influence of oil price on renewable energy stock prices: an analysis for entrepreneurs

expected result, as the presence of this pattern in equity returns is well documented in various studies (see, for example, Cont, 2001; Tsay, 2010). At the same time, oil price does not seem to represent a significant explanatory factor for the conditional volatility of renewable energy companies' stock prices. Moreover, this finding, coupled with the lack of Granger causality effects between oil returns and renewable energy companies' stock returns, indicates that oil markets and renewable energy markets are rather disconnected. This means that volatility in oil prices is not a serious factor of concern for the companies in the renewable energy industries. Consequently, the development of renewable energy businesses is less affected by potential shocks in the oil prices and markets. As a result, the exposure of companies and entrepreneurs in the renewable sector to an important source of macroeconomic volatility is reduced.

Given the higher vulnerability of entrepreneurs to macroeconomic shocks, our results provide them with a piece of good news, as they may focus more on developing their businesses rather that concentrating on risk management measures to manage aggregate economy problems. Nevertheless, since our analysis is implemented on global and regional indices that include both large companies in the renewable sector, but also mid and small size enterprises, it is difficult to generalize. More analysis is needed, in order to consider the specificities of each component of the renewable sector, as well as of the countries where these companies, and in particular entrepreneurial initiatives, operate.

\section{Acknowledgements}

The authors thank the anonymous reviewers and editor for their valuable contribution.

\section{Funding}

This work was cofinanced from the European Social Fund through Operational Programme Human Capital 2014-2020, project number POCU/380/6/13/125015 "Development of entrepreneurial skills for doctoral students and postdoctoral researchers in the field of economic sciences".

\section{Author Contributions}

The authors contributed equally to this work.

\section{Disclosure Statement}

The authors declare no conflict of interest. 
Vrînceanu, G., Horobet, A., Popescu, C., Belașcu, L., (2020)

The influence of oil price on renewable energy stock prices: an analysis for entrepreneurs

\section{References}

1. Bondia, R., Ghosh, S., Kanjilal, K., (2016), International crude oil prices and the stock prices of clean energy and technology companies: evidence from nonlinear cointegration tests with unknown structural breaks Energy, 101, 558-565

2. Bollerslev, T., (1986), Generalized autoregressive conditional heteroskedasticity Journal of Econometrics, 31(3), 307-327

3. Broadstock, D.C., Cao, H., Zhang, D., (2012), Oil shocks and their impact on energy related stocks in China, Energy Economics, 34, 1888-1895

4. Cont, R., (2001), Empirical properties of asset returns: stylized facts and statistical issues, Quantitative Finance, 1, 22-236

5. Dutta, A., (2017), Oil price uncertainty and clean energy stock returns: new evidence from crude oil volatility index, Journal of Cleaner Production, 164, 11571166

6. Engle, R., (1982), Autoregressive Conditional Heteroscedasticity with Estimates of the Variance of United Kingdom Inflation, Econometrica, 50(4), 987-1007

7. Granger, C.W.J., (1969), Investigating Causal Relations by Econometric Models and CrossSpectral Methods, Econometrica, 37, 424-438

8. Henriques, I., Sadorsky, P., (2008), Oil prices and the stock prices of alternative enegy companies, Energy Economics, 30, 998-1010

9. Kumar, S., Managi, S., Matsuda, A., (2012), Stock prices of clean energy firms, oil and carbon markets: A vector autoregressive analysis, Energy Economics, 34, 215-226

10. Managi, S., Okimoto, T., (2013), Does the price of oil interact with clean energy prices in the stock market? Japan and the world economy, 27, 1-9

11. MSCI, (2020), MSCI Global Alternative Energy Index (USD), Retrieved from https://www.msci.com/documents/10199/40bd4fec-eaf0-4a1b-bfc3-8ed5c154fe3c, Accessed on 4 March 2020.

12/ NASDAQ, (2020), Nasdaq Global Indexes, Retrieved from https://indexes.nasdaqomx.com/ Accessed on 29 February 2020

13. Omran, M.F., McKenzie, E., (2010), Heteroscedasticity in stock returns data revisited: volume versus GARCH effects, Applied Financial Economics, 10(5), 553560

14. Reboredo, J.C. (2014), Is there dependence and systemic risk between oil and renewable energy stock prices? Energy Economics, 48, 32-45

15. Reboredo, J.C., Rivera-Castro, M.A., Ugolini, A., (2017), Wavelet - based test of co-movement and causality between oil and renewable energy stock prices, Energy Economics, 61, 241-252

16. Sadorsky, P., (2012), Modelling renewable energy company risk, Energy Policy, 40, 39-48 
Vrînceanu, G., Horobet, A., Popescu, C., Belașcu, L., (2020)

The influence of oil price on renewable energy stock prices: an analysis for entrepreneurs

17. STOXX, (2016), Sector indices - DAXglobal Alternative Energy index, Retrieved from:

https://www.stoxx.com/document/Bookmarks/CurrentFactsheets/D1AM.pdf

Accessed on 29 February 2020.

18. Tsay, R.S., (2010), Analysis of Financial Time Series, Third edition, Hoboken: John Wiley and Sons, Inc.

19. US S\&P Indices, (2020), S\&P Global Clean Energy Index, Retrieved from: https://us.spindices.com/indices/equity/sp-global-clean-energy-index, Accessed on 29 February 2020

20. Wen, X., Guo, Y., Wei, Y., Huang, D., (2014), How do the stock prices of new energy and fossil fuels companies correlate? Evidence from China, Energy Economics, 41, 63-75 